\title{
A Interpretação Quântica do Mundo
}

\section{The Quantum Interpretation of the World}

RESUMO

A interpretação científica do mundo, embora sempre pautada em observações criteriosas dos fenômenos naturais, depende do estágio de evolução ou do nível cultural em que vivemos. O desenvolvimento da Mecânica Quântica é o mais belo exemplo disso, em que uma boa dose de criatividade foi necessária frente às dificuldades que a Física Clássica apresentava no final do século XIX. Os novos conceitos criados, como a universalidade da dualidade onda-partícula ou o princípio de incerteza norteando processos de medida, regem toda a matéria e não tem análogos na Física Clássica. Embora reinante em escalas subatômicas, recentemente tem-se evidenciado traços de propriedades quânticas fundamentais mesmo no mundo macroscópico.

Palavras-chave: Desenvolvimento científico e cultural. Mecânica Quântica. Dualidade onda-partícula.

\begin{abstract}
The scientific interpretation of the world, although based on natural phenomena, depends upon our evolutionary stage or cultural level. The development of Quantum Mechanics is one of the most beautiful example of that, in which a great deal of creativity was necessary to overcome the difficulties encountered by the Classical Physics in the end of the 19th century. The new concepts, like the universality of the wave-particle duality or the uncertainty principle in the measuring process, which govern the behavior of all matter, have no analogous in the Classical Physics. Although essential in the subatomic scales, traces of fundamental quantum properties are recently found even in the macroscopic world.
\end{abstract}

Keywords: Scientific and cultural development. Quantum Mechanics. Wave-particle duality. 


\section{INTRODUÇÃO}

A história da humanidade é, sem dúvida, maravilhosa quando analisada sob o ponto de vista das manifestações culturais em geral. O desenvolvimento científico é indissociável dessas manifestações e reflete a natureza humana como em qualquer outra atividade. Uma teoria científica é fruto das evidências que a natureza nos fornece através dos mais diversos fenômenos à nossa volta, mas também depende da criatividade humana, e, portanto, do seu estágio de evolução, trazendo características de certa época e limitações naturais decorrentes do momento e do lugar de sua criação. $\mathrm{Na}$ área da Física temos dois belos exemplos, a Mecânica Clássica e a Mecânica Quântica. Não são apenas duas teorias que explicam diferentes fenômenos, mas, antes de tudo, duas formas diferentes de pensar, que assim são porque foram criadas em momentos distintos de nossa evolução científica e cultural. Enquanto a Mecânica Clássica, por ter sido elaborada primeiro, interpreta tudo no Universo de forma mecânica e se pauta em dados e variáveis macroscópicas bem palpáveis oriundas de observações do dia a dia, a Mecânica Quântica é muito mais abstrata e lança mão de raciocínios extremamente elaborados, descrevendo a natureza com variáveis matemáticas nunca imaginadas pelas teorias clássicas, levando a um linguajar próprio para a interpretação dos fenômenos. Se causou estranheza no início, o desenvolvimento subsequente mais do que justificou a nova maneira de raciocinar no desvendar a natureza. Sem os frutos da Mecânica Quântica, o mundo hoje seria muito diferente, certamente muito mais limitado em desenvolvimento tecnológico e muitos processos fundamentais da natureza seriam mistérios aos nossos olhos. Nossa capacidade de criar novos materiais seria muito pequena. $\mathrm{O}$ que nos iluminou nessa caminhada para uma nova teoria que viria a ser essencial na compreensão da matéria foi, surpreendentemente, a natureza da luz, ou de forma mais abrangente, a natureza das radiações eletromagnéticas em geral. Vamos, então, primeiramente abordar alguns aspectos relevantes sobre a luz.

\section{A NATUREZA QUÂNTICA DA LUZ}

A luz é uma onda e isso foi demonstrado nos experimentos realizados já em 1803 por Thomas Young [10]. Médico de formação e preocupado com os problemas clínicos da visão, suas pesquisas sobre a luz o motivaram ao caminho da Física, dando muitas contribuições relevantes. Mostrou em um experimento histórico que a luz exibia difração e interferência ao passar por obstáculos; isso comprovaria, definitivamente, o caráter ondulatório da mesma, aparentemente encerrando uma discussão que vinha desde a época de Isaac Newton.

A natureza da luz, no entanto, só seria estabelecida por volta de 1860 com o físico inglês James Maxwell [9], que concluiu ser a mesma uma radiação eletromagnética, uma ondulação dos campos elétricos e magnéticos que se propagam no espaço com a espantosa velocidade de cerca de $300.000 \mathrm{~km} / \mathrm{s}$. Sendo uma onda, é caracterizada por uma frequência, $v$, que é o número de vezes que em um segundo a onda passa pelo seu valor máximo, e por um comprimento de onda, $\lambda$, que é a extensão espacial entre 
dois picos, ou vales, sucessivos da onda. Importante para as considerações que faremos abaixo é saber que, quanto maior $\nu$, menor $\lambda$. A diferença entre ondas como as de rádio, infravermelho, visível, ultravioleta, raios X etc. são os valores de $v$ ou $\lambda$, o que também é responsável pelas diferentes maneiras com que cada uma dessas radiações interage com a matéria. Por exemplo, para captar ondas de rádio usamos um fio metálico; para captar ondas visíveis usamos espelhos ou nossos olhos; já para raios $\mathrm{X}$ usamos certos cristais. Todas, no entanto, têm a mesma natureza eletromagnética e caminham com a mesma velocidade.

Ao final do século XIX, havia resultados experimentais precisos sobre a interação da matéria com as radiações eletromagnéticas, particularmente com a chamada radiação de corpo negro, que é um caso específico em que há um equilíbrio térmico entre a matéria aquecida a uma certa temperatura e a radiação por ela emitida. No entanto, a melhor explicação para os resultados experimentais do espectro dessa radiação dada pela Física Clássica era uma catástrofe, a ponto de a teoria prever que uma pequena fogueira poderia nos matar de tanta radiação ultravioleta que sairia da mesma.

Desafiado a entender qual seria o mecanismo responsável por essa radiação de corpo negro, Max Planck, num trabalho memorável publicado em 14 de dezembro de 1900 [4] e que marcaria o nascimento da Física Quântica, mostra que uma onda eletromagnética interage com a matéria através da troca de valores definidos de energia, como se trocasse pacotes, ou quanta, de energia. Para explicar os resultados experimentais, Planck concluiu que cada quantum deveria conter a quantidade $h v$ de energia, sendo $h$ hoje denominada constante de Planck, uma das mais importantes constantes universais conhecidas. Ele ganharia o prêmio Nobel em 1918 por essa contribuição. Ironicamente, um professor dele o teria desestimulado à carreira de físico dizendo que nessa área tudo já teria sido descoberto! Na verdade, Planck estava prestes a revolucionar a Física. Sua explicação para a radiação de corpo negro rompia conceitos preestabelecidos, válidos em outras circunstâncias, mas que não podiam ser aplicados irrestritamente à matéria. Suas conclusões surpreenderam até mesmo a ele, mas se mostraram corretas, como ficou demonstrado em diversos experimentos que se sucederam. Seus resultados têm impacto até mesmo em Astrofísica ou Cosmologia, pois permitem a determinação de parâmetros como temperatura ou raio estelar. A radiação cósmica de micro-ondas que permeia o Universo segue o padrão da radiação de corpo negro e, com os resultados de Planck, pode-se calcular a temperatura dessa radiação, hoje da ordem de poucos Kelvins.

A revolução científica que estava sendo iniciada por Planck teria continuidade imediata com Einstein* [2] que, já em 1905, interpreta o resultado de Planck e mostra que a energia de uma onda eletromagnética é transportada por partículas, posteriormente denominada de fótons. Assim, cada fóton transporta, ou é, um quantum de energia luminosa. Conclusão, as ondas eletromagnéticas possuem um caráter dual, exibindo características ondulatórias como interferência e difração, como mostrou Young, ou corpusculares, como estabeleceram Planck e Einstein. Esses conceitos viriam a explicar uma gama de experimentos, como o efeito fotoelétrico e o espalhamento de raios $\mathrm{X}$, e serviram de base para a construção de dispositivos importantes, como os painéis fotovoltaicos ou as modernas máquinas fotográficas e TVs digitais. Einstein ganharia o prêmio Nobel em 1921 pela sua explicação do efeito fotoelétrico.

A Interpretação Quântica do Mundo
*O artigo, de suma importância para a Física, merece seu registro à parte: EINSTEIN, A. Über einen die Erzeugung und Verwandlung des Lichtes betreffenden heuristischen Gesichtspunkt. Annalen der Physik, v.17, p.132-148, 1905. Este e outros artigos de Albert Einstein estão disponíveis na web para consulta pública em: <http://einstein annalen. mpiwg-berlin.mpg.de/annalen/ chronological/>. 
Estava, então, consolidada a ideia da quantização da energia, que seria crucial para o estabelecimento da Mecânica Quântica, particularmente nos trabalhos subsequentes de Niels Bohr, em 1925, sobre a constituição atômica da matéria [1]. A ideia de que existem grandezas quantizadas, no entanto, é bem anterior aos trabalhos de Planck e Einstein, como veremos a seguir.

\section{A NATUREZA ATÔMICA DA MATÉRIA}

A natureza granular da matéria já era considerada pelos filósofos gregos em cerca de 450 a.C. e até cunharam a palavra átomo para a menor parte indivisível da matéria que ainda guardava sua propriedade original. No entanto, iniciativas para se provar a existência do átomo só aparecem no século XVII com Gassendi e Hooke, mas de forma simplória. Com Avogadro, em 1811, a ideia da quantização da massa ganha atenção, pois é formulada de maneira quantitativa. Junto com a teoria cinética dos gases e os estudos de Einstein sobre o movimento browniano, ficou evidente já no início do século XX que a matéria não é contínua, mas constituída de átomos que se juntam em moléculas e dão forma e propriedade aos corpos.

Outra grandeza importante que se apresenta na forma quantizada é a carga elétrica de um corpo, sendo o valor fundamental a carga do elétron, uma das partículas mais importantes da natureza, descoberta por J. J. Thomson [8] em 1897 e que lhe rendeu o Prêmio Nobel em 1906. Thomson dirigia o Laboratório Cavendish, um dos mais importantes da época. Dentre seus colaboradores, sete ganharam o Prêmio Nobel. Sua descoberta foi de extrema importância, pois qualquer carga elétrica é um múltiplo da carga do elétron. Aliando seus resultados aos de P. Zeeman, de 1896, concluiu-se que o elétron era parte integrante do átomo e, portanto, este era divisível. Outras partículas foram identificadas como constituintes dos átomos, como os prótons e os nêutrons. No começo do século XX já eram estabelecidas as quantizações da massa, da carga e da energia, o que representava um grande passo para a elaboração de uma nova Mecânica, a Mecânica dos Quanta.

\section{A NATUREZA ONDULATÓRIA DA MATÉRIA}

O surgimento da Mecânica Quântica foi decorrência de dificuldades que a Mecânica Clássica apresentava ao explicar diversos fenômenos conhecidos ao final do século XIX, como o comportamento térmico da matéria ou a interação desta com as radiações eletromagnéticas. Niels Bohr [1], em 1925, preocupado em entender os espectros de linhas coloridas emitidas por diversos materiais, principalmente o do gás hidrogênio, elabora uma teoria quântica em que introduz um conceito novo, a saber, que os átomos trocam energia com o ambiente através de transições eletrônicas que se processam pela absorção ou emissão de fótons pelos elétrons. Sua teoria era ousada para a época e, a despeito do sucesso, infelizmente ainda continha traços da Mecânica Clássica, o que é compreensível, pois se tratava de uma fase de transição de uma teoria antiga para uma 
moderna. Era também muito limitada ao gás hidrogênio, não fornecendo bons resultados para outros elementos químicos. Com Werner Heisenberg e Erwin Schrödinger, temos a formulação atual da teoria quântica, com conceitos inteiramente novos. Com Paul Dirac, essa teoria se junta ao formalismo da Relatividade Especial de Albert Einstein e dá origem à Teoria Quântica de Campos, fundamental na compreensão dos fenômenos envolvendo partículas elementares. $\mathrm{O}$ funcionamento de modernos aceleradores, como o extraordinário LHC, se fundamenta nos resultados dessa fusão de teoria quântica com a da relatividade.

Mas, afinal, que ideias revolucionárias são essas que levaram à criação da Mecânica Quântica e que abriram um caminho tão frutífero ao conhecimento científico, que deram origem a novas tecnologias, como os lasers, permitiram entender e construir novos materiais como os semicondutores, ou nos levaram a prever entidades tão complexas sobre o mundo em que vivemos, como os bósons de Higgs, e mais do que qualquer outra teoria científica, nos faz pensar tanto sobre a natureza do mundo em que vivemos e qual o nosso papel ou influência nele?

Para ilustrar a ideia básica por trás da Mecânica Quântica, comecemos com um simples experimento do dia a dia, o de descrever o movimento de um carro numa rua. Todos sabem fazer isso muito bem, basta informar a cada instante onde ele se encontra e qual a velocidade em que ele está. Podemos usar marcas predefinidas ao longo da rua para medir distâncias e, com a ajuda de um cronômetro, calculamos sua velocidade, que nada mais é do que a taxa com que o espaço muda com o tempo. Mas essas operações de medida envolveram algo que, neste exemplo em particular, não demos atenção: foi preciso ver o carro, isto é, observar a luz refletida nele! O desprezo pela interação carro luz é natural, uma vez que, obviamente, o impacto da luz não altera em nada a posição ou a velocidade do carro, pois transfere um impulso ou uma energia absolutamente desprezível ao mesmo, já que possui uma massa da ordem de toneladas. Com posições e velocidades medidas a cada instante podemos saber a trajetória do carro e saber até mesmo quais forças estão atuando sobre o mesmo, ou seja, sabemos com precisão tudo sobre o movimento do objeto em estudo. Importante aqui é reconhecer que a observação ou as medidas executadas no carro em nada alteram seu estado de movimento: sua trajetória é a mesma, quer o observemos ou não. A Mecânica Clássica evoluiu bastante quando aplicou esse conceito de trajetória ao macrocosmo e um bom exemplo disso é a descrição precisa dos movimentos dos corpos no nosso Sistema Solar, cujo tamanho é cerca de 1010 metros (o número 1 seguido de 10 zeros). Vale lembrar que Edmund Halley previu, usando a Teoria Clássica da época, o regresso do famoso cometa que leva o seu nome para a véspera do Natal de 1758 .

O sucesso foi tão grande ao nível cósmico que a Mecânica Clássica parecia universal. Era natural, portanto, que se tentasse explicar fenômenos originários no interior da matéria, em escala atômica. Acontece que um átomo mede cerca de 10-10 metros (1 sobre 1 seguido de 10 zeros), por consequência, ínfimo, se comparado às escalas em que a Mecânica Clássica foi desenvolvida e comprovada. Não é surpreendente, portanto, que dificuldades iriam aparecer nessa jornada em direção ao microcosmo. A Ciência, porém, evolui principalmente quando enfrenta desafios e, neste caso, culminou com a criação de uma nova Mecânica. 
Vejamos como a Mecânica Clássica tenta tratar a questão do movimento atômico. Gostaríamos de estudar o movimento de um átomo, marcando sua posição e velocidade em funções do tempo, como fizemos para o carro. "Simples" - um físico clássico diria - "preciso vê-lo; assim, ilumino-o e analiso a luz refletida a cada instante". Mas, diferentemente do carro, um átomo é muito pouco massivo; para se ter uma ideia de sua massa, um carro tem cerca de 1030 átomos! Como consequência de sua leveza, a luz acaba transferindo energia para o átomo, que tem sua velocidade alterada substancialmente. Para evitar essa situação, pensaríamos em usar uma radiação energeticamente bem fraca, ou seja, de frequência muito baixa (lembre-se, energia é proporcional à frequência). Isso garantiria que o átomo não tivesse sua velocidade alterada apreciavelmente, já que estaria absorvendo pouquíssima energia. Mas, como mencionamos acima, frequência baixa corresponde a uma radiação de grande comprimento de onda, ou grande extensão espacial, e, assim, ao analisar a radiação refletida pelo átomo, esta não traria informação precisa de sua localização; seria como tentar adivinhar a presença de um barquinho em alto mar olhando para as ondas de grande extensão espacial que chegam à praia!

Em resumo, a observação no mundo microscópico tem uma limitação natural: se tentarmos medir a velocidade com precisão, perderemos noção da posição do objeto; se tentarmos medir a posição com precisão, usando uma radiação de comprimento de onda muito pequeno (como raios $\mathrm{X}$ ), como esta terá necessariamente frequência muito alta, transferirá muita energia ao objeto e, assim, não saberemos sua velocidade. Essas limitações não são tecnológicas, isto é, não serão contornadas com o avanço de qualquer técnica, mas são intrínsecas à natureza. Não se restringem ao mundo microscópico, mas é nele que ganham importância crucial. Existem outros pares de variáveis, além de posição e velocidade, que também sofrem de limitação análoga. Esses pares são ditos obedecerem ao princípio de incerteza de Heisenberg. Na opinião de muitos, é a existência desse princípio que mais distingue a Mecânica Clássica da Quântica.

Uma consequência imediata dessa limitação na determinação simultânea e precisa da posição e velocidade de um objeto é que não podemos mais utilizar o conceito de trajetória e tudo que dela depende. Com isso, nossa descrição das interações entre os corpos precisa ser modificada, pois se fundamenta no conhecimento da distância entre eles. Isso não afeta apenas áreas da Física, mas é crucial também em Química e em Biologia Estrutural, que se baseiam no entendimento das interações entre diferentes átomos ou moléculas. Então, era necessário um novo conceito para descrever a evolução temporal de partículas em escala atômica ou subatômica ou uma nova Mecânica que descrevesse o comportamento dos corpos com variáveis que pudessem ser medidas. A procura dessa teoria culminou na elaboração da Mecânica Quântica.

Neste momento do desenvolvimento científico, em que uma nova Mecânica estava para nascer, ficou clara a importância da criatividade humana. Pensou, em 1924, o nobre príncipe francês Louis de Broglie [5], que se iniciou em História, mas se rendeu aos encantos da Física por influência de seu irmão, o físico Maurice de Broglie: se com os trabalhos de Planck e Einstein estamos evidenciando que uma onda eletromagnética tem caráter corpuscular, isto é, carrega fótons, por que partículas materiais como átomos, elétrons etc. também não podem exibir um caráter ondulatório? Assim, a dualidade onda-partícula seria uma característica universal, presente nas ondas e na matéria 
em geral. De Broglie fez essa proposta em sua tese de doutorado; foi um ato de súbita inspiração - como ele mesmo menciona - e de pura criatividade, já que não havia dados experimentais que evidenciassem diretamente isso. O próprio de Broglie sugeriu como comprovar sua proposição, que se mostraria verdadeira e de enorme importância, pois viria a nortear os pensamentos científicos da época. Experimentos confirmaram sua proposta e a onda associada a cada partícula material seria interpretada posteriormente como relacionada à probabilidade de localização da partícula. Essa onda sofre difração e interferência como qualquer outra onda, o que é essencial para descrever o movimento das partículas. Isso é coerente com a falta de trajetória das mesmas, pois onda não tem trajetória bem definida. Vale ressaltar que a interpretação posterior dada a essas ondas não era compartilhada pelo próprio de Broglie, o que evidencia que um ato criativo não segue uma linha lógica necessariamente, mas pode abrir as portas para que outros possam formular a estrutura lógica em que uma teoria deve se fundamentar. De Broglie foi laureado com o Nobel de 1929, sendo o primeiro a receber tal prêmio decorrido de resultados de uma tese de doutorado. Na verdade, os trabalhos da tese não foram de início bem recebidos, mas depois que Einstein leu a tese e fizera um alto elogio ao trabalho, teve aceitação e clamor pela banca examinadora. Seu orientador foi o importante físico francês Paul Langevan.

Curiosamente, um dos experimentos importantes a confirmar o caráter ondulatório do elétron foi feito por G. P. Thomson, filho de J. J. Thomson, que havia, em 1890, descoberto o elétron a partir de um experimento em que o mesmo se mostrava como partícula! Ele recebe o Nobel em 1937 juntamente com Davisson, outro a demonstrar, de modo independente, a mesma característica ondulatória do elétron. Diversos outros experimentos foram e são, ainda, realizados e todos confirmam a natureza dual de partículas em escala atômica.

Em razão desse caráter dual, uma partícula não executa uma trajetória bem definida de um ponto a outro do espaço; só podemos afirmar qual a probabilidade que ela possui de estar numa dada posição a cada instante. $O$ valor dessa probabilidade é obtido sabendo-se a amplitude da onda intrinsecamente associada à partícula. Apenas uma medida pode revelar se ela está ou não num determinado ponto do espaço. Essa medida, no entanto, altera substancialmente a onda associada a ela e, como consequência, seu estado de movimento, conforme discorremos acima. Nesse sentido, o observador, aqui entendido como o agente que faz a medida, é parte integrante do experimento. $\mathrm{Na}$ Mecânica Clássica, há sempre o pressuposto de que a influência do observador pode ser minimizada ao extremo de ele ser desconsiderado. Na Mecânica Quântica, isso não só é impossível como é essencial que o observador seja considerado como parte do sistema em estudo.

Sem o conceito de trajetória, muito do que havíamos aprendido na Física Clássica precisa de revisão. Por exemplo, como fica a nossa visão da constituição do átomo? Aprendemos nos primeiros ensinamentos de Ciências que um átomo é constituído de um pequeníssimo núcleo formado de prótons e nêutrons e com elétrons girando ao redor em trajetórias circulares. Essa ideia de trajetória já trazia dificuldades mesmo antes do advento da Mecânica Quântica, pois um elétron tem carga elétrica e numa trajetória circular, devido a sua aceleração, deveria perder sua energia por irradiação e 
cair no núcleo do átomo em cerca de um nanossegundo! Nada ou ninguém existiria no Universo segundo esse cenário. A Mecânica Quântica resolve esse problema, abolindo o conceito de trajetória e descrevendo o movimento do elétron em termos da probabilidade de ele ser encontrado em cada ponto do espaço. O mapeamento espacial dessa probabilidade ao redor do núcleo atômico resulta no que chamamos de orbitais atômicos. Essa noção é fundamental em praticamente toda a Química; seria extremamente difícil, senão impossível, descrever ligações químicas com o conceito clássico de trajetórias. Hoje, descrevemos a formação de moléculas pela superposição ou junção de orbitais atômicos; e mais, com a ideia de orbitais, não apenas entendemos o comportamento da matéria, mas diferentes compostos são projetados para terem propriedades específicas, como supercondutores, semicondutores, superfluidos, os fantásticos nanotubos de carbono e mais recentemente até fármacos, materiais que estão começando uma revolução em nosso modo de vida.

A fronteira entre a escala em que a Mecânica Quântica deve ser aplicada e a escala em que a Mecânica Clássica passa a valer não é bem definida. Não há valores bem definidos de tamanho ou massa que dividam o mundo clássico do quântico, mas é certo que, embora as propriedades das substâncias dependam da natureza quântica de seus constituintes, não vemos no nosso mundo macroscópico a matéria exibir caráter ondulatório. Os objetos ao nosso redor exibem trajetórias bem definidas e não se parecem com ondas ou se comportam como tal! O que faz com que a dualidade intrínseca ao nível atômico desapareça ao nível macroscópico? Os físicos argumentam que a dualidade exige uma coerência da onda de probabilidade, que é perdida quando a partícula interage com o ambiente em que ela se encontra. Esse ambiente é constituído de outras partículas e radiações, sempre presentes principalmente quando se realiza uma medida, pois neste caso algum instrumento ou observador, necessariamente, está interferindo no estado da partícula. Esse ambiente causa uma decoerência na onda e uma consequente perda da informação quântica ao nível macroscópico. Em palavras simples, quando muitas partículas estão juntas, via de regra elas não se organizam num estado coerente por muito tempo, deixam de exibir propriedades individuais e, portanto, passam a se comportar como clássicas. No entanto, experimentos recentes estão em curso, procurando evidenciar traços quânticos individuais deixados por essas partículas no ambiente [11]. O entendimento dessas questões é de grande relevância, por exemplo, na elaboração de sistemas de criptografia baseados em estados atômicos. Isso dará confiabilidade muito maior na transmissão de dados sigilosos entre dois pontos. Também será relevante na construção de uma nova geração de computadores, que utilizam o emaranhamento de estados quânticos $[3,7]$ no lugar dos tradicionais bits o e 1, e promete aumentar sobremaneira a capacidade de processamento computacional atual. Além de ampliar nossa compreensão sobre a teoria quântica, essas questões e experimentos permitirão que no futuro tenhamos uma intuição muito maior sobre o mundo quântico, a ponto de podermos, quem sabe, considerá-lo mais natural. É notável como as novas gerações já estão tratando os fenômenos quânticos com novos olhos.

Em estágios iniciais dos estudos em Mecânica Quântica é natural nos perguntarmos se, um dia, iremos entender esses conceitos tão abstratos, tão diferentes daqueles que estamos acostumados no dia a dia. A meu ver, muito mais produtivo nesses estágios 
é compreender as razões que levaram os seus protagonistas a elaborarem um cenário dualista, em que a matéria tem seu comportamento regido por uma onda de probabilidade e que uma onda luminosa transporta energia através de partículas. Essas ideias, sem sombra de dúvida, foram consequências de uma evolução científica, respaldada firmemente em observações da natureza e em resultados de importantes experimentos. Mas devemos reconhecer que essas observações não foram, por si, o que definiu nossa visão do mundo. Nosso estágio cultural desempenhou papel indissociável.

Podemos dizer que foi de extrema genialidade a criação de conceitos quânticos como a dualidade onda-partícula ou podemos dizer que talvez seja tão difícil de entendê-los porque são apenas fragmentos dentro de uma teoria mais abrangente ainda a ser elaborada e que, no momento, ainda não temos como imaginá-la, mas que será arquitetada em momento oportuno de nossa evolução. Sendo assim, hoje temos uma interpretação quântica do mundo, mas amanhã estaremos num novo estágio de evolução, com novos experimentos conhecidos, e nossa interpretação do mundo certamente sofrerá influência desse novo momento de nossa história! Obviamente que nossa cultura também evolui sob influência do desenvolvimento científico. $\mathrm{O}$ emaranhamento entre cultura e ciência é inevitável e bem-vindo, pois promove a evolução consciente de uma sociedade. Sem a cultura, não saberíamos a razão da ciência; sem a ciência, não conheceríamos a beleza da natureza.

Embora a Mecânica Quântica tenha seus postulados bem definidos, ela dá margem a diferentes interpretações. Desde sua criação, apareceram diversas correntes de interpretação, todas em geral procurando entender o conceito de onda de probabilidade associada a cada partícula [6]. Teria essa onda uma realidade ou seria apenas um instrumento matemático para se obter informações do estado de movimento das partículas, ou de valores de medidas realizadas sobre as mesmas? Seriam onda e partícula objetos separáveis ou indissociáveis? Esse fascinante e complexo tópico de estudo, com grande apelo filosófico, tem sido amplamente explorado tanto do ponto de vista teórico como experimental. Os resultados certamente nos farão repensar o mundo em que vivemos.

\section{REFERÊNCIAS BIBLIOGRÁFICAS}

[1] BOHR, N. On the Constitution of Atoms and Molecules. Philosophical Magazine, v. 26, p. 1-25, 1913.

[2] EINSTEIN, A. On a Heuristic Point of View about the Creation and Conversion of Light. In: HAAR, D. T. (Org.). The Old Quantum Theory. Cambridge: Pergamon Press, 1967, p.91-106.

[3] KON, D. Ligações Perdidas. Pesquisa Fapesp, São Paulo, v. 136, p.56-57, 2007.

[4] KRAGH, H. Max Planck: the reluctant revolutionary. Physics World, p. 31-35, dez. 2000.

[5] NOBEL FOUNDATION. The Nobel Prize in Physics 1929: Louis de Broglie. Sweden: Nobel Foundation, s/d. Disponível em: <http://www.nobelprize.org/ nobel_prizes/physics/laureates/1929/broglie-bio.html>. Acesso em: 19 mar. 2013.

[6] PESSOA JÚNIOR, O. Conceitos de Física Quântica. São Paulo: Editora 
Livraria da Física, 2003.

[7] PIVETTA, M. Os fantasmas dos fótons. Pesquisa Fapesp, São Paulo, v. 123, p.58 59, mai. 2006.

[8] THOMSON, G. P. J. J. Thomson, discoverer of the electron. New York: Doubleday \& Co., 1964.

[9] UOL EDUCAÇÃO. Físico escocês: James Clerk Maxwell. São Paulo: Universo On Line, s/d. Disponível em: <http://educacao.uol.com.br/biografias/jamesclerkmaxwell.jhtm >. Acesso em: 19 mar. 2013.

[10] WIKIPEDIA. Thomas Young (scientist). San Francisco: Wikimedia Foundation, s/d. Disponível em: <http://en.wikipedia.org/wiki/Thomas_young (scientist)>. Acesso em: 19 mar. 2013.

[11] ZORZETTO, R. Sobre gatos, fótons e mundos estranhos. Pesquisa Fapesp, São Paulo, v. 202, p. 18-25, dez. 2012.

VALTER LUIZ Líbe Ro professor do Instituto de Física de São Carlos (IFSC) e atual diretor do Centro de Divulgação Científica e Cultural (CDCC) - R. 9 de Julho, 1227 - Centro - CEP 13560-042 - São Carlos-SP - e-mail: libero@ifsc.usp.br. 